\title{
One woman is still not enough
}

\author{
Japanese science needs its women more than ever. Why doesn't it treat them accordingly?
}

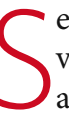
even years ago, Mitiko Go, a biophysicist then at Nagoya University, told Nature about a disturbing experience she had had at a meeting of the university's Division of Biological Science (see Nature 410, 404-406; 2001). The academics were considering a female applicant for a vacant chair, and one male member said: "I'm sorry to have to say this in front of Dr Go, but one woman is enough."

Go thought she might be scolded for relating the story (and indeed she says she was accused of "tarnishing the honour of the university"), but she was about to retire from the university and felt the time had come to say something radical.

Times have changed. Far from retiring, Go is now president of the prestigious Ochanomizu University in Tokyo and a member of the Council for Science and Technology Policy, the country's highest science body, which is chaired by the prime minister. Go and others have implored the government to do more in support of women. The science and education ministry has responded.

Funding regulations, for example, now allow women on extended maternity leave to postpone grants rather than losing them. But the biggest change came in 2006 with a new budget to promote women in science, which has already jumped from $¥ 665$ million (US\$6.2 million) in 2006 to $¥ 1.8$ billion this year. It supports programmes that encourage girls at high school to get into science. And it includes special competitive grants for 80 women returning to science after giving birth.

The biggest chunk of cash goes towards the development of 'model programmes'. Each year since 2006, the science ministry has funded ten new centres to the tune of $¥ 50$ million per year to develop comprehensive programmes for the support of women scientists. Last week, women, and some men, from across the country met at Ochanomizu University to discuss the progress of these programmes. Princess Akishino attended and the mood was upbeat. Posters were sprinkled with phrases such as "Girls, be cheered". One logo features a woman jumping a hurdle. “The change has been epoch-making," says Go.

But there is something that remains token about all these gestures.
Ochanomizu is the only one of Japan's 87 national universities with a female president. Only four have female vice-presidents. Go is one of two female members of the 15-member Council for Science and Technology Policy. Slight advances over the past few years have brought the ratio of women scientists to $12.4 \%$ of the total - a paltry number that pits Japan against South Korea at the bottom of developed nations and far below the European Union and US averages of about $30 \%$.

It's not just the numbers. Visit most Japanese labs or go to academic conferences, and the women will generally recede into the background. Are their opinions being sought? Are their creative energies being tapped? There are no numbers on this, but the answer is undoubtedly 'no'.

Japan needs its women like never before. There are fewer students than available university seats and a trend away from

"Making women active members of the scientific workforce means rethinking the work-life balance." mathematics and science among students. The society is greying, and there remains an unwillingness to open the borders to foreigners on a large scale.

Many problems affect Japanese women and men alike. Original ideas from women are less likely to be taken seriously — but junior laboratory members in general are not encouraged to risk being wrong, to offer outlandish (aka creative) ideas. And no matter how much economic support there is for mothers, dirty looks, snide comments and a general attitude of unspoken disrespect aimed at one who leaves at 5 or 6 p.m. - even if it is to pick up the kids - will make lab life difficult. Making women active members of the scientific workforce means rethinking the work-life balance in general.

As part of her model programme, Go encourages all researchers at Ochanomizu to work 9 to 5. To do so, she has changed rules and faculty meeting schedules. This is by no means a revolution. But it may be a step in undoing a culture that has handicapped Japan by keeping roughly half its creativity under wraps. Too bad it can't happen faster.

\section{Forward with biofuels}

\section{Cellulosic biofuels are part of an emerging US energy policy, from which other regions can learn.}

\footnotetext{
$\prod^{\text {out }}$ he energy law signed on 19 December by President Bush lays out a bold mandate for biofuels. As well as broadly ensuring that the United States remains home to the largest biofuels industry in the world in the coming decade, the law takes an important step forward by recognizing that all biofuels are not created equally. From 2016, refiners must begin to switch to cellulosic ethanol and other advanced biofuels that do not rely on corn sugars, and these fuels will have to meet new standards for reducing
}

greenhouse-gas emissions compared with standard petrol.

That's the good news. The bad news is that, in the short term, this mandate will merely bolster the corn ethanol empire, which is far from ideal given the accumulation of evidence against the current generation of biofuels. The latest research suggests that any fuel that competes with food also encourages farmers around the world to expand their operations into native lands. Doing so causes a spike in emissions - from carbon once locked up in plants and soil - that might well outweigh the long-term benefits of the biofuels themselves.

Cellulosic ethanol, which can be produced from prairie grasses, municipal waste or just about any carbon-based materials, might well resolve these problems by expanding the feedstock away from food crops (see page 880). Exciting research is also under way on a third generation of synthetic biofuels - designer fuels secreted by 